\title{
LEPROSY DISEASE IN NEPAL : KNOWLEDGE AND NON-COMPLIANCE OF PATIENTS
}

\author{
Chalise S C \\ Department of Health Services/MOH, Kathmandu, Nepal
}

\section{ABSTRACT}

Non-compliance among leprosy patients has always been a problem in Nepal. Many researches on drug compliance has indicated that if a patient understands well about his /her disease and its treatment, he /she is more likely to be motivated to take the whole prescribed course of treatment properly. It is widely believed that the understanding and behavior of patients in relation to drug compliance are largely influenced by their socio-economic condition and level of knowledge.

In order to determine the socio-economic characteristics of non-compliant leprosy patients and their level of knowledge of leprosy disease and treatment, a non-intervention study was carried-out in Dhanusha - a high prevalent district in Nepal bordering India. A total of 57 non-compliant leprosy cases were selected using systematic sampling method on the basis of available clinical records and an interview-schedule was used for data collection. The result shows that the majority of non-compliant cases were illiterate, laborers by occupation and from poor economic class family background (73.7\%).

Data revealed that majority did not understand the cause of the disease and were not aware of the duration of treatment. It was interesting to note that an overwhelming majority $(\mathbf{9 4 . 7 \% )}$ ) were having strong belief that the disappearance of sign/symptoms was the only meaning of the "cure of leprosy disease". In view of this, it is strongly recommended that the patient education and counseling, public/community awareness program should be improved and further strengthened. A socio-economic rehabilitation program with vocational/trade training to leprosy patients or their family members should be arranged to up-lift their socio-economic status.

Key Words: Leprosy, Patient Knowledge, Compliance.

\section{INTRODUCTION}

At present, Nepal is moving ahead towards the attainment of national target of "leprosy elimination" as a public health problem (to attain a level of prevalence below one leprosy case per 10,000 population) and thus, His Majesty's Government has taken it as a priority program and concentrating all its efforts on the formulation and implementation of an effective and qualitative leprosy control services throughout the country.

Address for correspondence :

Suraj Chandra Chalise

Leprosy Control Division, Department of Health Services/MoH, Kathmandu, Nepal

Email: chalises@hotmail.com

Received Date : $22^{\text {nd }}$ August, 2003

Accepted Date : $23^{\text {rd }}$ April, 2005 
In implementation of effective and qualitative leprosy control program, it is necessary not to overlook the key aspect of noncompliance. Its rate is an important indicator of the performance and success of a disease control program. In such a program, if non-compliance rate is high, it indicates that the aspects of case holding and compliance with treatment are poor. However, it is apparent that the overall compliance among leprosy patients is far from satisfactory. ${ }^{1}$

According to the National Manual for Leprosy Elimination, a Paucibacillary (PB) patient must complete 6 monthly doses of Multidrug Therapy (MDT) within 9 months and a Multibacillary (MB) patient must complete 12 monthly doses of MDT within 18 months. ${ }^{2}$ Any PB patient three (>3) months without MDT for any MB patient more than six $(>6)$ months without MDT for are labeled "Non-compliant cases" and these patients are recorded under the category of "Irregular" for the purpose of Health Management Information System of Ministry of Health. ${ }^{3}$ They need to restart the full course of treatment and remain as leprosy cases that increase the risk of disease transmission in the society, allowing to develop high grade of disability/ deformity. These cases may also create negative attitude towards leprosy treatment that are available free of cost in all government health institutions.

The problem of non-compliance has been reported universally, ${ }^{4}$ though the extent and its causes vary widely. In Nepal, noncompliance among leprosy patients has been a problem in almost all districts. However, the Terai districts bordering India are experiencing high non-compliance rate.

At the beginning all cases were registered for leprosy treatment at units/centers of the district with a hope of cure. Over the treatment period, they started to be absent for treatment and finally became non-compliant. This indicates that there are some strong reasons, which affects the behavior of leprosy patients towards the treatment. Generally, it is believed that if the patient understands well about his/her disease and treatment, he/she is more likely to be motivated to finish the whole course of treatment correctly. Many studies have found that the patient's understanding and behavior in relation to compliance are influenced by various categories of factors. ${ }^{4,5,6,7,8,9}$ Among these, socio-economic factors are major factors contributing to noncompliance of leprosy patients.

The overall objectives of this study were to determine the socioeconomic characteristics of non-compliant leprosy cases in Dhanusha district and their knowledge of leprosy disease and its treatment.

\section{MATERIALS AND METHODS}

\section{Study area}

The study area was Dhanusha district, one of the Terai districts of Nepal. The study considered non-complaint cases from areas served by 2 of the 4 primary health centers, 8 of 10 health posts and 1 district clinic run by the district health office (DHO) at district headquarters.

\section{Sampling}

All non-compliant leprosy cases of the district $(n=436)$ that had failed to complete full course of MDT within prescribed period of time were considered as study population. Keeping in view of the large study area and other limitations, only 57 noncompliant cases were chosen ( $\mathrm{SE}=10 \%$ ) as sample size. Using Systematic Sampling Method on the basis of a sampling frame constructed from the Lalgadh Leprosy Hospital, Lalgadh and District Health Office, Dhanusha, the selection of sample study population were completed.

However, 57 non-compliant individuals from 2 PHCs and 8 HPs including 1 DHO clinic area were contacted and information collected with the help of semi-structured interview schedule. The interview data were augmented by information collected during informal discussions with non-compliant cases.

\section{RESULTS}

\section{Socio-economic characteristics}

Of the sample population $(\mathrm{n}=57), 58 \%$ were multibacillary leprosy cases and $42 \%$ were paucibacillary cases, which were residing in health post and $\mathrm{PHC}$ areas that cover the rural population of the district. Table I shows that majority (80.7\%) of the non-compliant cases were from the age group of 15-56 years, which is known as economically very active age group.

It was found that the majority (12.2\% more than joint family) of total non-compliant leprosy cases belonged to nuclear family consisting of both biological parents and their children. About $44 \%$ lived in a joint family, which included more than two generations or having extended family members' e.g. married sisters and/or brothers. In Table II, the social characteristics of the non-compliant cases are summarized.

Table I: Age structure of study population according to type of their leprosy disease

\begin{tabular}{ccccc}
\hline Age group & MB type & PB type & Total & \% \\
\hline $1-14$ years & 1 & 3 & 4 & 7.0 \\
$15-28$ years & 3 & 2 & 5 & 8.8 \\
$29-42$ years & 11 & 16 & 27 & 47.4 \\
$43-56$ years & 13 & 1 & 14 & 24.5 \\
$57-70$ years & 5 & 2 & 7 & 12.3 \\
\hline Total & $\mathbf{3 3}$ & $\mathbf{2 4}$ & $\mathbf{5 7}$ & $\mathbf{1 0 0 . 0}$ \\
\hline
\end{tabular}


Table II: Main social characteristics of the sample study population $(\mathbf{n}=57)$

$\begin{array}{llll}\text { Sex } & : \text { Male } 40(70.2 \%), & \text { Female } 17(29.8 \%) \\ \text { Age } & : \text { Mean age 39.2 years } & \\ \text { Religion } & : \text { Hindu 52 }(91.2 \%) & \text { Muslim 5 }(8.8 \%) \\ \text { Literacy } & : & \text { Illiterate 39 }(68.4 \%) & \text { Literate } 18(31.6 \%) \\ \text { Marital status } & : & \text { Unmarried 6 }(10.5 \%) & \text { Married } 45(79 \%) \\ & & \text { Widowed 6 }(10.5 \%) & \\ \text { Family type } & : & \text { Nuclear 32 }(56.1 \%) & \text { Joint } 25(43.9 \%) \\ \text { Family size } & : & \text { Mean size 6.9 members } & \end{array}$

In economic aspect, Table III shows that about $81 \%$ noncompliant cases were actively involved in some form of income generating activities. However, majority were involved in labor/ daily wage work that is known as a temporary/seasonal work in nature.

Table III: Main occupation of the sample study population (Non-compliant cases)

\begin{tabular}{lcc}
\hline \multicolumn{1}{c}{ Occupation } & Frequency & \% \\
\hline Laborers /Daily wage earners & 30 & 52.6 \\
Own agriculture & 12 & 21.0 \\
Student & 4 & 7.0 \\
House wife & 4 & 7.0 \\
Shop keeper & 3 & 5.3 \\
Office job & 1 & 1.8 \\
Very old /retired & 3 & 5.3 \\
(Unable to do job) & & \\
\hline \multicolumn{2}{c}{ Total } & $\mathbf{5 7}$ \\
\hline
\end{tabular}

For the purpose of study, the economic status of non-compliant cases have been classified in four categories such as lower, lower-middle, middle, and high economic class. Lower class represents those families whose income was not sufficient for their basic family needs and lower-middle represented families whose income was sufficient but could not save their earnings for future basic needs. Similarly, middle class represented family with sufficient income and have reasonable amount of saving while high class represents rich family with capacity of enough saving. In general, both lower and lower-middle economic class represents poor economic class background.

In order to ascertain the economic class of non-compliant cases, all respondents were asked to rate the economic class of their

Table IV : Economic Class of Sample study population

\begin{tabular}{lcc}
\hline \multicolumn{1}{c}{ Economic class } & Frequency & \% \\
\hline Lower & 23 & 40.4 \\
Lower - middle & 19 & 33.3 \\
Middle & 11 & 19.3 \\
High & 4 & 7.0 \\
\hline \multicolumn{1}{c}{ Total } & $\mathbf{5 7}$ & $\mathbf{1 0 0 . 0}$ \\
\hline
\end{tabular}

family after explaining the set meaning of each economic class. The results are shown in Table IV

\section{Knowledge of Leprosy disease}

In order to assess the level of knowledge of leprosy disease and its treatment, all respondents were asked various questions and responses were summarized in the following tables V, VI, VII, VIII, IX.

Table V : Cause of disease as known to the sample population

\begin{tabular}{lcc}
\hline \multicolumn{1}{c}{ Cause of disease } & Frequency & \% \\
\hline God's wish/sin & 19 & 33.6 \\
Micro organism & 8 & 14.1 \\
Bad-blood & 6 & 10.5 \\
Hereditary & 2 & 3.5 \\
Don't know & 22 & 38.6 \\
\hline \multicolumn{1}{c}{ Total } & $\mathbf{5 7}$ & $\mathbf{1 0 0 . 0}$ \\
\hline
\end{tabular}

Table VI : Sign/symptoms of leprosy disease as known to sample population

\begin{tabular}{lcc}
\hline \multicolumn{1}{c}{ Sign/symptoms } & Frequency & \% \\
\hline Anesthetic skin patch & 41 & 71.9 \\
Loss of sensation in hands/feet & 7 & 12.3 \\
Tingling /burning sensation & 3 & 5.3 \\
Painless wound & 3 & 5.3 \\
Ulceration and deformity & 2 & 3.5 \\
Don't know & 1 & 1.7 \\
\hline \multicolumn{1}{c}{ Total } & $\mathbf{5 7}$ & $\mathbf{1 0 0 . 0}$ \\
\hline
\end{tabular}

Table VII : Meaning of 'Cure of the disease' as believed by sample population

\begin{tabular}{ccc}
\hline Meaning of 'Cure' & Frequency & \% \\
\hline $\begin{array}{c}\text { Disappearance of sign/symptoms } \\
\text { Don't know }\end{array}$ & 54 & 94.7 \\
\hline Total & 3 & 5.3 \\
\hline
\end{tabular}

Table VIII : Belief of sample population on the curability of leprosy disease

\begin{tabular}{lcc}
\hline Belief on the curability & Frequency & \% \\
\hline Yes (Is curable) & 40 & 70.2 \\
No (Is not curable) & 3 & 5.3 \\
Don't know & 14 & 24.5 \\
\hline \multicolumn{1}{c}{ Total } & $\mathbf{5 7}$ & $\mathbf{1 0 0 . 0}$ \\
\hline
\end{tabular}

Table IX : Duration of treatment as known to sample population according to type of their disease

\begin{tabular}{lccccc}
\hline Duration of & \multicolumn{2}{c}{ MB } & \multicolumn{2}{c}{ PB } & \multirow{2}{*}{ Total } \\
\cline { 2 - 5 } \multicolumn{1}{c}{ treatment } & No & \% & No & \% & \\
\hline 1-5 months & - & - & 1 & 4.2 & 1 \\
6 months & 4 & 12.1 & 10 & 41.7 & 14 \\
12 months & 12 & 36.3 & 1 & 4.2 & 13 \\
24 months & 5 & 15.2 & - & - & 5 \\
More than & 7 & 21.2 & 5 & 20.8 & 12 \\
24 months & & & & & \\
Don't know & 5 & 15.2 & 7 & 29.2 & 12 \\
\hline \multicolumn{1}{c}{ Total } & $\mathbf{3 3}$ & $\mathbf{1 0 0 . 0}$ & $\mathbf{2 4}$ & $\mathbf{1 0 0 . 0}$ & $\mathbf{5 7}$ \\
\hline & & & & & \\
\hline
\end{tabular}




\section{DISCUSSION}

The study has revealed various facts about the socio-economic characteristics of non-compliant leprosy cases and their understanding about the disease and its treatment.

An overwhelming majority (80.7\%) of the non-compliant cases in the study were from the age of 15-56 years, which is considered as an economically active age group. The study has shown that majorities of non-compliant cases were male (70.2\%), hindu (91.2\%), married (79\%), and illiterate $(68.4 \%)$ having the mean size of 6.9 family members. The large numbers were from nuclear type family $(56.1 \%)$ consisting of both biological parents and their children while about $44 \%$ were in a joint family, which enclosed more than two generations or having extended family members e.g. married sisters /or brothers.

Majorities (52.6\%) were engaged in labor /daily-wage work, and were from poor economic class family background (73.7\%). In other studies of non-compliance in India, it was also found that the majority of non-compliant cases were laborers and wage earners. ${ }^{10,11}$ The loss of daily wage if they visited the clinic forced them to become "irregular".

The study revealed that about $86 \%$ of the non-compliant cases do not have scientific concept of leprosy. About $39 \%$ were not sure of what caused the disease. A significant proportion (33.3\%) of non-compliant cases believed that the disease was caused due to God's wish or due to sin committed by them in the past life. A study of help-seeking behavior in Nigeria recorded a similar finding i.e. majority of patients used traditional beliefs to explain the cause of leprosy. ${ }^{12}$ It is to be noted that only about $14 \%$ non-compliant cases knew the real cause of the disease i.e. caused by a bacterium or a "micro organism".

Regarding knowledge on sign /symptoms of the disease, $71.9 \%$ non-compliant cases mentioned "anesthetic skin patch," (it is considered as one of the cardinal sign of leprosy) while $26.4 \%$ have mentioned other sign /symptoms. It is interesting to note that majority (94.7\%) of non-compliant cases were having strong belief that the disappearance of sign/symptoms is the only meaning of the 'cure of the disease'. This also clearly indicates their low level of understanding of treatment and its outcome. In leprosy, the loss of sensation and established deformity / disability may remain after "Cure of the disease". These aspects would not be improved by chemotherapy i.e. Multidrug therapy (MDT). Other additional measures like physiotherapy, self-care procedures, and /or surgical interventions besides chemotherapy are necessary.
In this study, the majority (70.2\%) of non-compliant cases had shown their belief that leprosy is curable while $24.5 \%$ were not aware about its cure. However, $5.3 \%$ of non-compliant cases had exposed their strong negative belief on it. Among the sample population, only $36.3 \%$ of MB type and $41.7 \%$ of PB type noncompliant cases mentioned correct duration (12 months for MB type and 6 months for PB type) of their treatment while majorities of non-compliant cases were not aware of the duration of treatment. In a study carried-out in South India, Rao has also reported similar findings. ${ }^{13}$

\section{CONCLUSIONS}

The study found that the majority of non-compliant cases were socio-economically poor and having deprived family background. These conditions can barricade the development of positive behavior of leprosy patients towards drug compliance.

The present study reveals that community is still associating God's wish and sin with the occurrence of the disease. This may strongly contribute towards non-compliance of leprosy cases because they believe that man-made modern medicine can not challenge God's wishes. They also have strong belief that the "Cure of leprosy disease" means disappearance of its entire sign/symptoms.

A significant proportion of non-compliant cases were not aware about the cure of the disease and some were having strong negative belief on it. These facts indicates that traditional beliefs in the community about leprosy and reveals the non-permeation of health education/public awareness activities in the community. Thus it is to be concluded that despile launching community/public awareness program and implementing various activities for health services providers and receivers in the Dhanusha district, the level of knowledge of non-compliant cases about leprosy disease and its treatment is indigent.

\section{RECOMMENDATIONS}

In order to improve the socio-economic condition of noncompliant leprosy cases and their level of understanding about the disease, the following recommendations are made:

I. Encourage further operational research in the domain of non-compliant behavior of leprosy patients.

II. Make necessary arrangements to provide vocational /trade training to leprosy patients or their family members with an objective to uplift their socio-economic status. 
III. Introduce effective counseling as part of the therapy at all treatment centers /clinics in order to alleviate patient's fear, doubt and anxiety in relation to disease, treatment and its outcome. It should be made a routine practice to maintain drug compliance at high level.

IV. The areas of deficiency in currently used leprosy related information, education and communication (IEC) activities need to be identified, so that appropriate and effective measures to strengthen these areas can be applied.

V. Public awareness /health education activities should be improved and build-up on the understanding of community perception of the disease and on cultural meaning of the disease within the community.

VI. Train and mobilize Village Health Workers, Mother and Child Health Workers and Female Community Health Volunteers to educate patients, their families, and communities so their level of knowledge of disease can be improved. These workers and volunteers are the key catalyst of change at rural level and can play a potential role in changing help-seeking behavior of rural population in Nepal.

\section{ACKNOWLEDGEMENT}

The study is generously supported by the German Foundation for International Development (DSE), Germany and Netherlands Leprosy Relief (NLR), The Netherlands. The author is thankful to Dr. C. Jincen, CEDHA, Tanzania for her valuable guidance and to Dr. J. P. Baral, Leprosy Control Division, Department of Health Services, Kathmandu for his encouragement and the family of Lalgadh Hospital /Nepal Leprosy Trust and District Public Health Office, Dhanusha for the author their sincere support in conducting the study. Wishes to express his warmest thanks to many leprosy patients who shared their time to help them learn from their experiences.

\section{REFERENCES}

1. Jacobson, RR. Treatment. In: Hastings, R. C. (Ed.), Leprosy (Medicine in the Tropic Series), Longman group, UK, 1989: 193-222.

2. Ministry of Health. National Manual for Leprosy Elimination in Nepal. Third Edition, Leprosy Control Division, Department of Health Services, Kathmandu, Nepal, 2001: 21-24.

3. Ministry of Health. National Manual for Leprosy Elimination in Nepal. Third Edition, Leprosy Control Division, Department of Health Services, Kathmandu, Nepal, 2001: 25-26.

4. Donovan, JL. and Blake, DR. Patient non-compliance: deviance or reasoned decision-making? Social Science and Medicine, 1992; 34: 507-513.

5. Ellard, GA. Drug Compliance in the treatment of Leprosy. Leprosy Review, 1981; 52: 201-203.

6. Homedes, $\mathrm{N}$ and Ugalde, A. Patients' Compliance with treatments in the thirld world. What do we know? Health Policy and Planning, 1993; 8 (4): 291-314.

7. Kannan, N and Sivram, M. Variables Influencing Regularity of Leprosy Patients in Attending Ttreatment Clinics. Indian Journal of Leprosy, 1992; 64: $505-511$.

8. Langhorne, $P$ et al. Factors influencing clinic attendance during the multi drug therapy of leprosy. Leprosy Review, 1986; 57: 17-30.

9. Mull, JD et al. Culture and 'Compliance' among leprosy patients in Pakistan. Social Science and Medicine, 1989; 29: 799-811.

10. Koticha, KK et al. Problems of Urban Leprosy Control with Special Reference to Case Holding. International Journal of Leprosy, 1984; 52 : 482-487.

11. Gopalakrishnan, S. Dropouts during treatment for leprosy. Indian Journal of Leprosy, 1986; 58: 431 - 440.

12. $\mathrm{N}$ van de weg et al. Explanatory models and help-seeking behavior of leprosy patients in Adamawa State, Nigeria. Leprosy Review, 1998; 69: 382-389.

13. Rao, KV. Leprosy in Rural India. Manak Publications, New Delhi, India, 1992. 